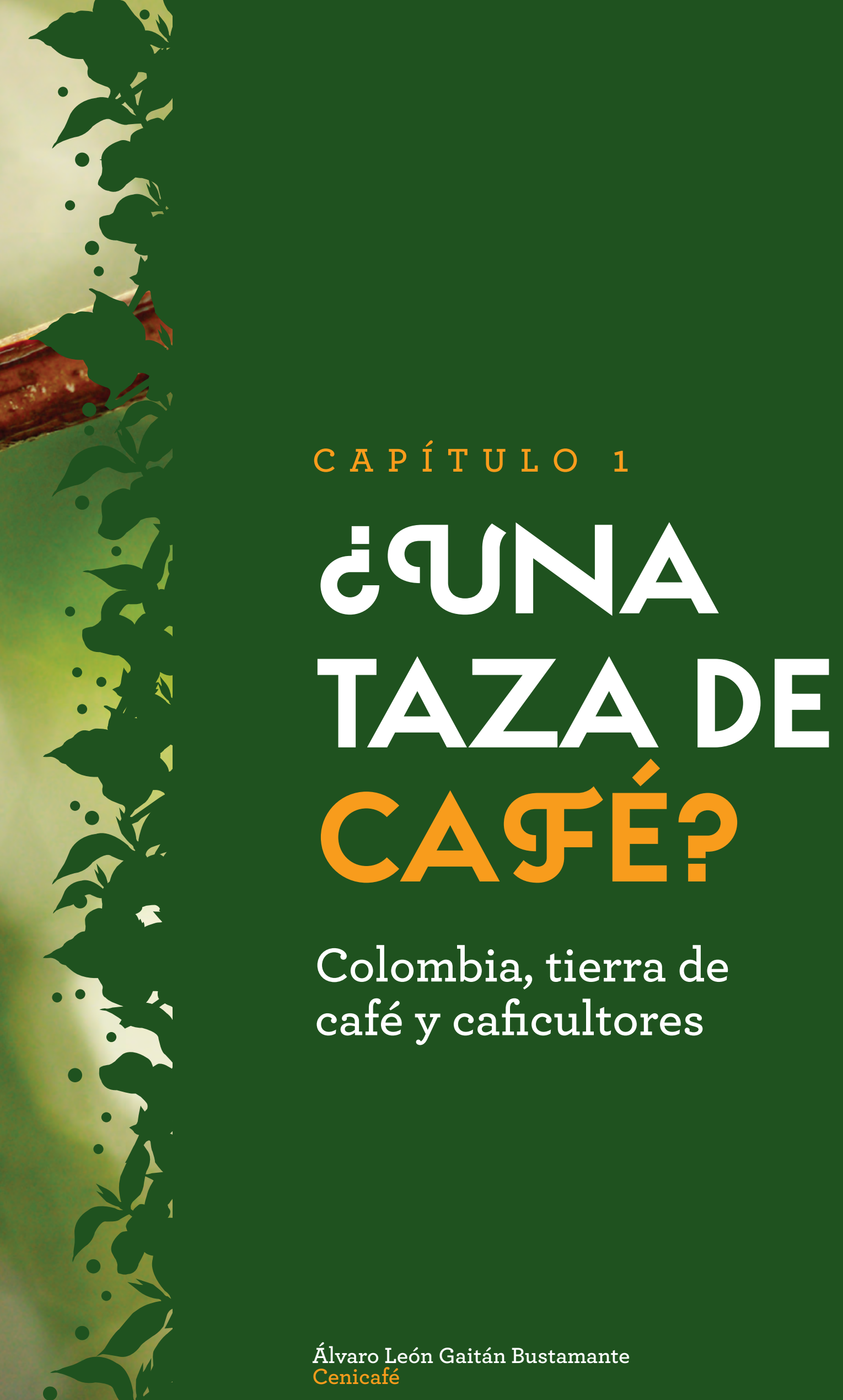

Alvaro León Gaitán Bustamante Cenicafé 
El café es el producto más conocido de la tierra colombiana. Desde la primera exportación, registrada en 1835, Colombia ha sido la fuente por excelencia de cafés suaves lavados a escala mundial. Los cafés colombianos no solo son reconocidos internacionalmente por su calidad, sino también admirados por la identidad de sus productores, por su cultivo sostenible en las imponentes laderas de los Andes, por su procesamiento amigable con el ambiente y por el beneficio en el tejido social del país. Esta espléndida bebida congrega e invita a socializar, sin importar la hora ni el lugar. 


\section{LA SEMILLA DEL CAFETO}

La bebida de café es una infusión preparada a partir de su semilla, previamente tostada. La semilla de café es una nuez alargada y plano-convexa, cuyas dimensiones pueden variar entre 10 y $18 \mathrm{~mm}$ de largo y entre 6.5 y $9.5 \mathrm{~mm}$ de ancho. Cada semilla tiene una grieta muy característica que cruza longitudinalmente su cara interna, conocida como "sutura coffeanum". La semilla está constituida por el embrión, que se encuentra ubicado en la cara abultada del grano y es recubierto por el endospermo, donde se almacenan proteínas, azúcares, aceites y alcaloides como la cafeína. Estos componentes confieren a la bebida sus propiedades organolépticas, es decir, las que pueden ser percibidas por nuestros sentidos.

El endospermo está cubierto por una capa delgada y brillante de células, denominada "pe- lícula plateada". Esta capa a su vez está envuelta por el pergamino llamado endocarpio, que le confiere la resistencia estructural a la semilla.

Normalmente, cada cereza de café tiene dos semillas rodeadas por la pulpa o cáscara (el pericarpio). La cáscara presenta dos capas, una interna carnosa llamada mesocarpio, y una externa, el exocarpio. Los constituyentes del pericarpio son los que le dan el color al fruto de café: verde cuando contiene principalmente clorofila y rojo cuando predomina el contenido de cianidina, que indica su estado de maduración.

Los frutos de café se desarrollan en los nudos, donde se bifurcan las ramas del cafeto. Estos son producidos solo una vez. De esta manera, los nuevos frutos deben producirse en nuevos nudos, que van apareciendo tanto en las puntas de las ramas, a una tasa aproximada de un nudo por mes, como en nuevas ramas que van creciendo a

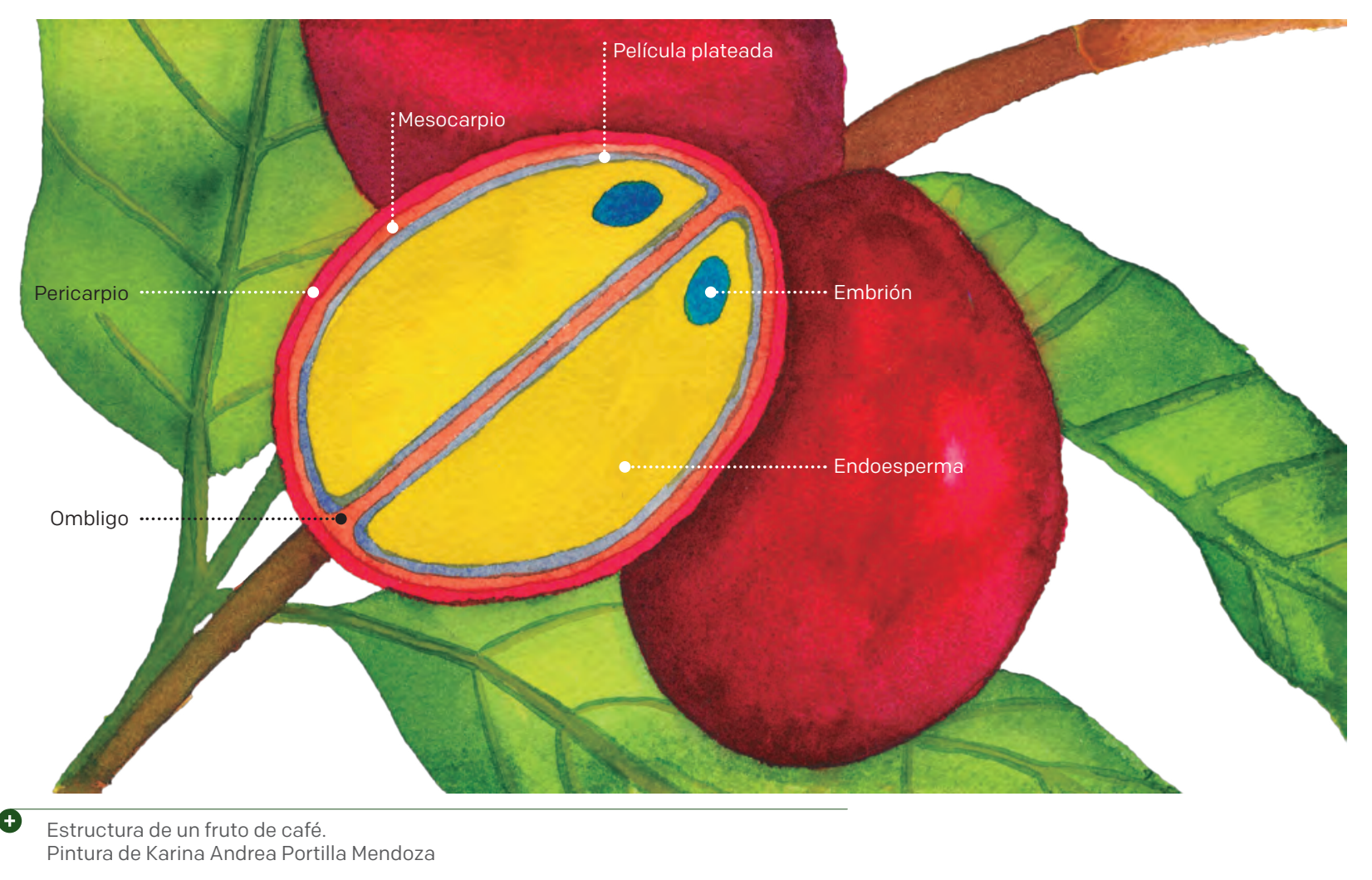


partir del tronco del arbusto (ramas primarias) o de ramificaciones de ramas ya existentes (ramas secundarias). En el ambiente tropical colombiano, el proceso de desarrollo de un fruto, desde la floración hasta la maduración, se toma en promedio 260 días, dependiendo de las condiciones climáticas, en particular de la temperatura y la disponibilidad de agua.

La calidad de una bebida de café depende de varios factores que, en conjunto, resultan en una infusión balanceada, con cuerpo, dulzor y distintos niveles de acidez. Estos factores dependen de la variedad cultivada, el manejo agronómico, la interacción con el clima, la calidad de la cosecha, el proceso de beneficio, el almacenamiento y la tostión (torrefacción), y finalmente, de la misma preparación para el consumidor final.

Los caficultores colombianos han adquirido prestigio mundial por cultivar café en las laderas de las montañas. Este café es producido de manera casi artesanal, utilizando el proceso de secado, y da lugar al llamado "café pergamino seco". A partir de ese momento, el café se comercializa y trilla para que la industria torrefactora lo ponga en la mesa de millones de personas que día a día degustan una bebida estimulante y rica en aroma y sabores.

Considerando la variedad de café cultivada como el primer factor que define la calidad, el mercado del café se desarrolló internacionalmente a partir de dos especies: Coffea arabica, que produce cafés suaves o arábigos, asociados a lugares con temperaturas medias de $22{ }^{\circ} \mathrm{C}$, y Coffea canephora, productora de los cafés robustos, mucho más rústicos y adaptados a climas más calientes.

Disposición de los nudos donde crecen los 


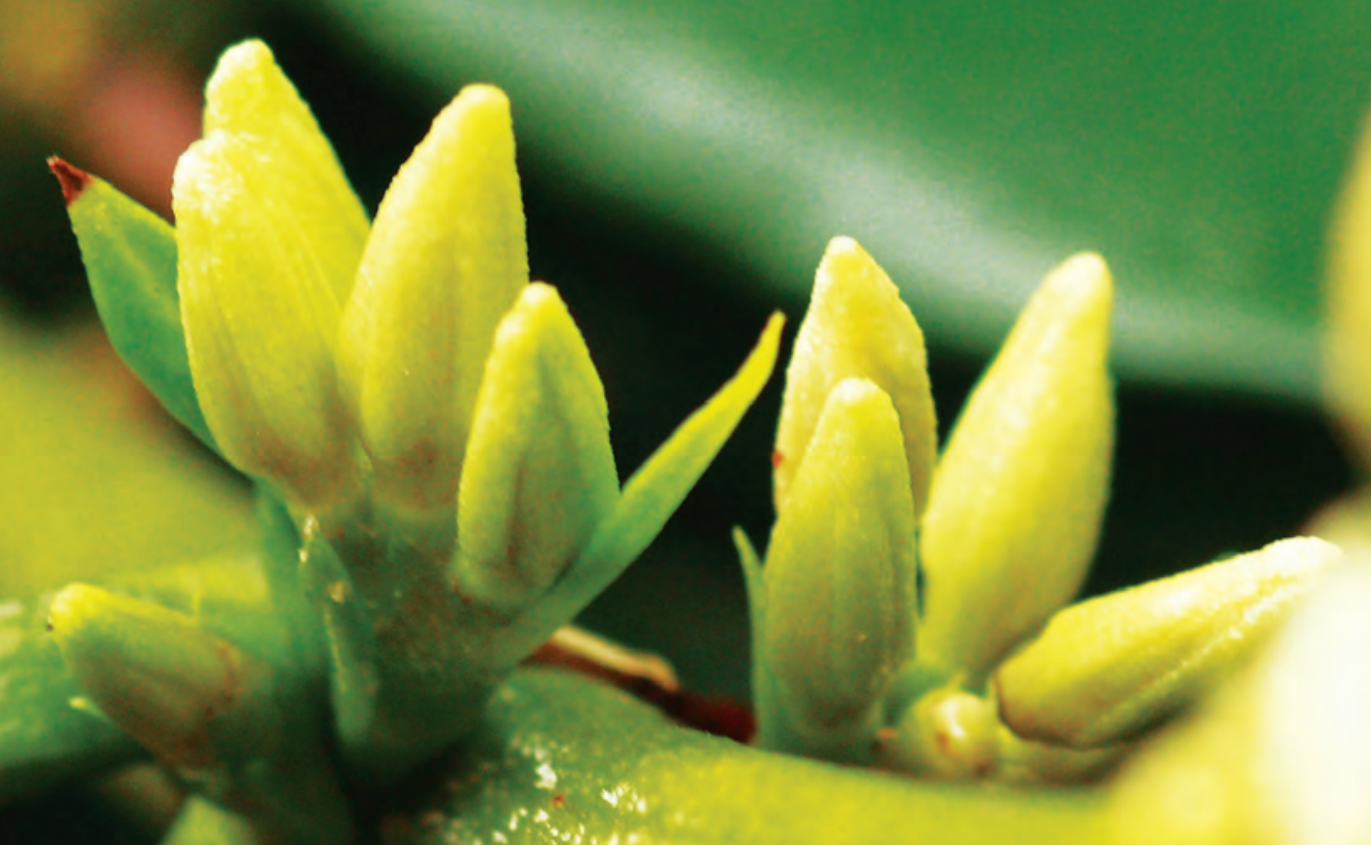

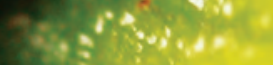

E 


\section{Ciclo del café}

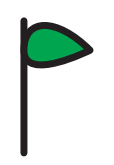

Crecimiento

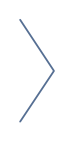

Cosecha

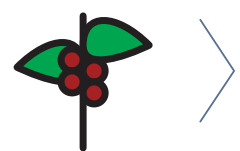

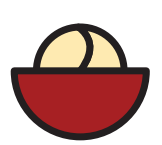

Beneficio

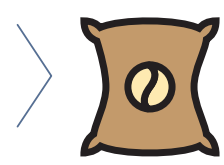

Empaque

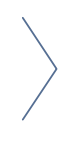

Comercialización

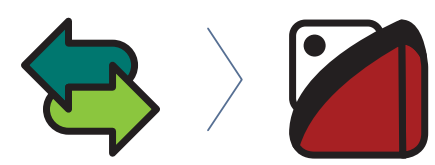

Transporte

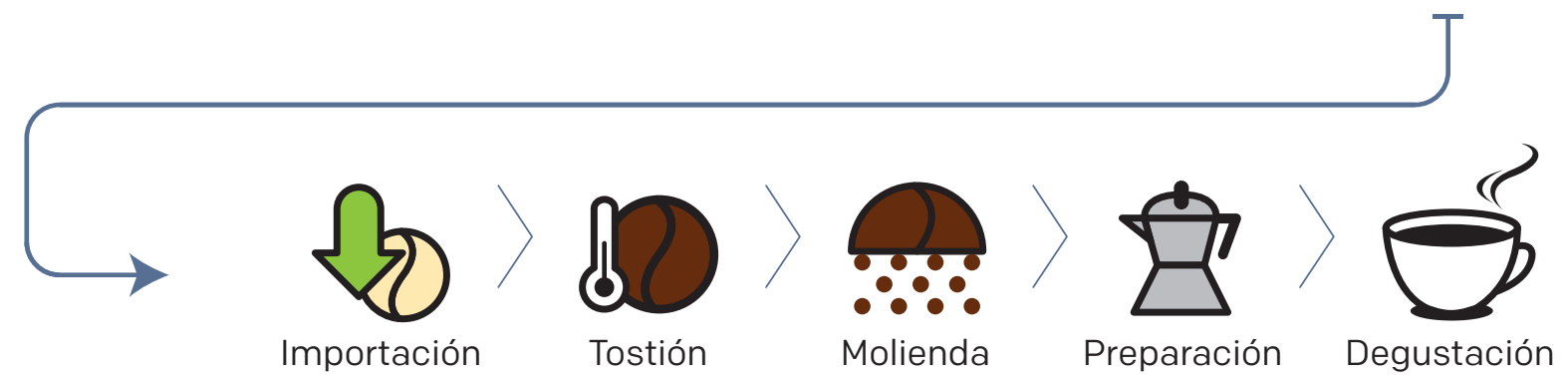

$\oplus$

Ciclo del café

DIFERENCIAS ENTRE LAS VARIEDADES ARÁBICA Y ROBUSTA

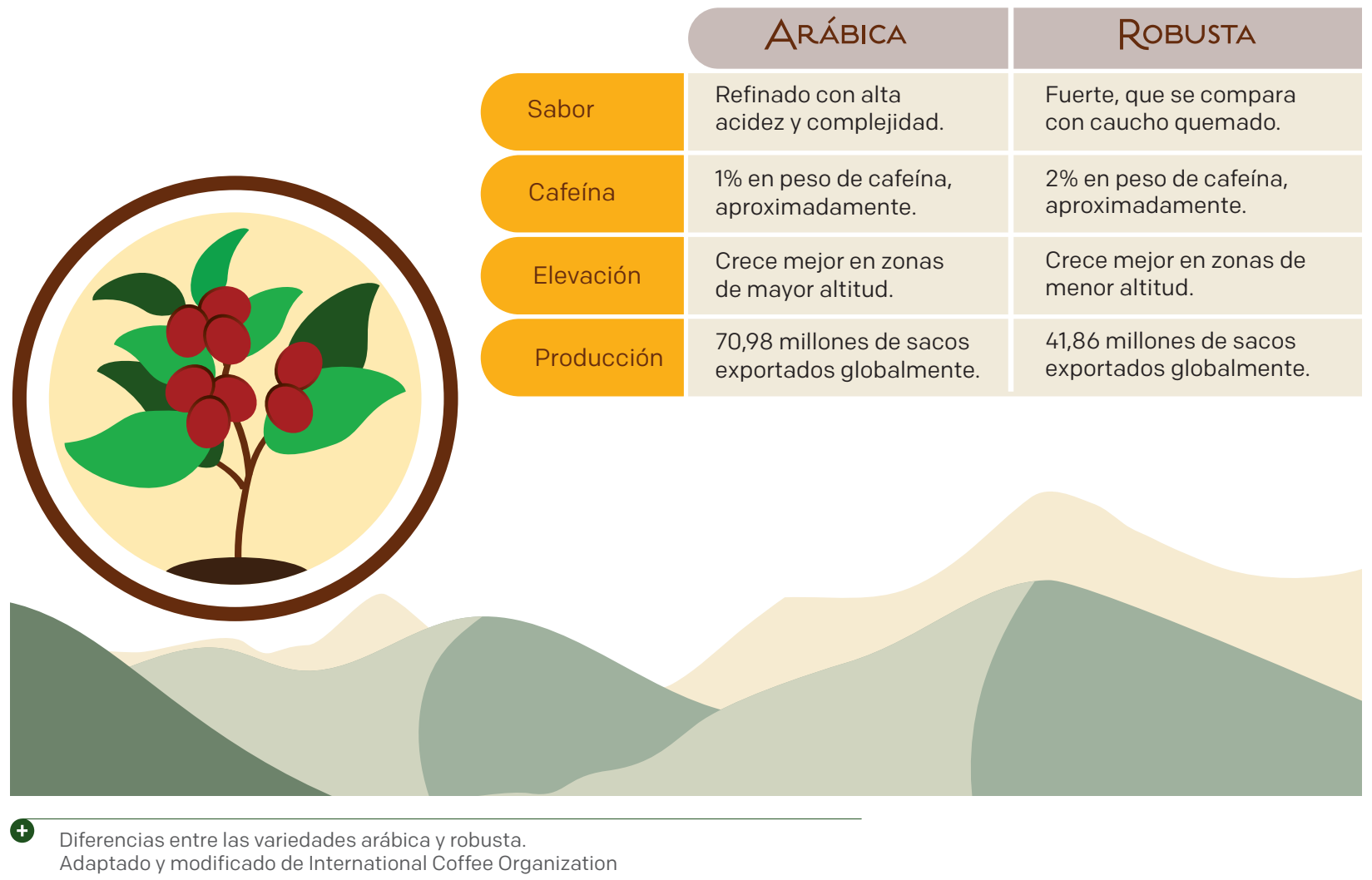




\section{○UN POCO DE HISTORIA}

Colombia tomó la ruta de los cafés suaves cuando las primeras semillas de Coffea arabica arribaron, a finales del siglo XVIII, provenientes del Caribe, adonde habían llegado luego de una larga migración de más de quinientos años desde su sitio de origen, en lo que hoy es Etiopía y Sudán del Sur, pasando por la península arábica (Yemen) y los jardines botánicos de Ámsterdam y París. Fueron los holandeses los encargados de esparcirlo por la India, Ceilán y el Caribe.

A principios del siglo XVI, un oficial de la Marina francesa logró adquirir y preservar una planta de café, que llevaría en su viaje de regreso a las Américas. A partir de este momento la planta fue cultivada en las islas del Caribe y comenzó a expandirse por nuestro continente. A lo largo de este viaje no hubo una marcada diversidad genética, y el resultado fue la presencia de plantas muy similares entre sí en todas las plantaciones, y no solo de Colombia, sino del continente americano. Así conformó una variedad conocida como Típica, que luego localmente sería denominada pajarito o nacional.

Una segunda fuente de semillas de Coffea arabica provino de la isla Reunión o Bourbón, una colonia francesa en el océano Índico. Esta

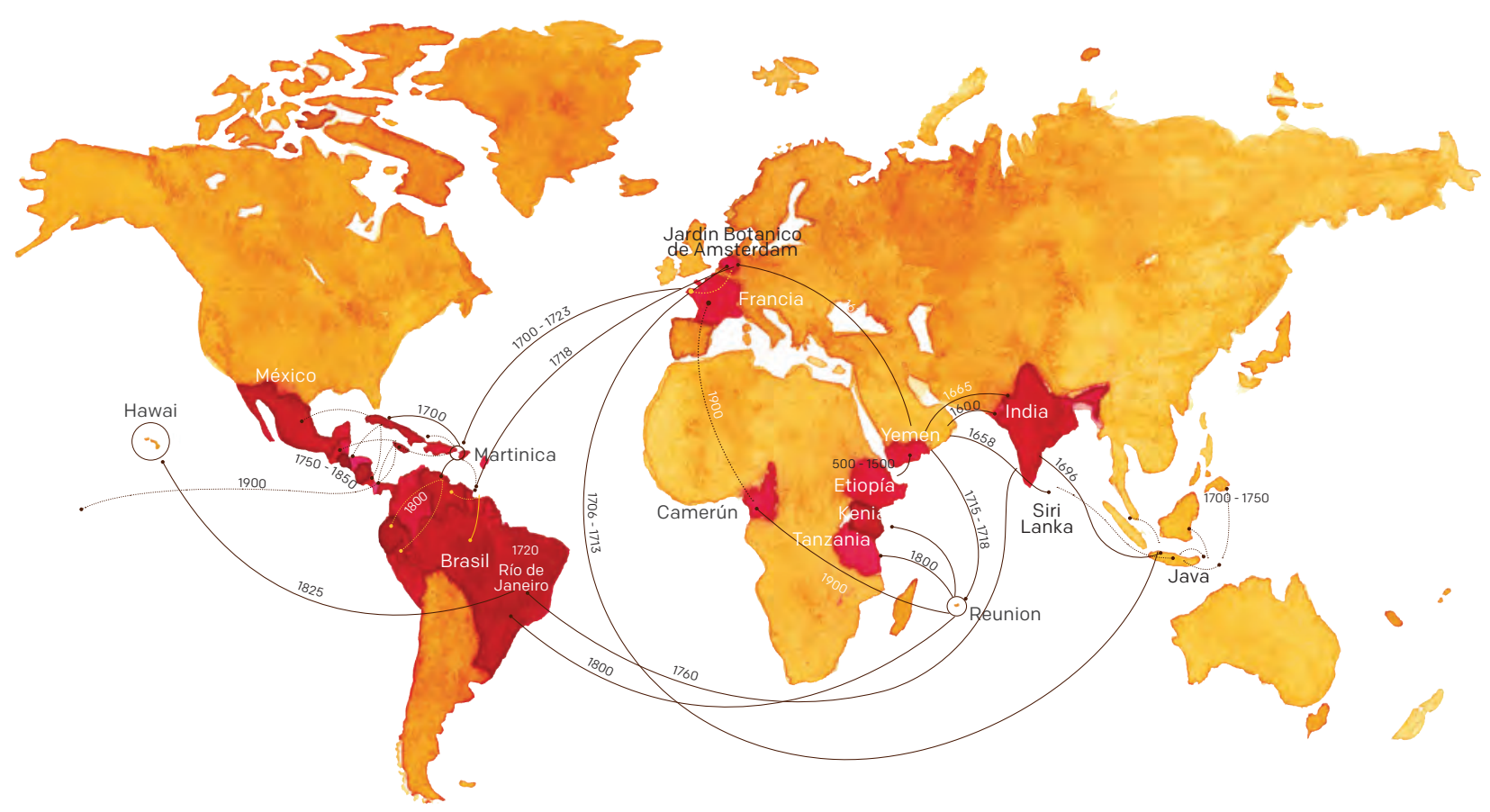

Esquema temporal de la migración del café hasta la llegada a nuestro territorio. Adaptado y modificado de Specialty Coffee Association of America:

https://store.sca.coffee/products/the-historic-distribution-of-coffea-arabica?variant=14724490054 Pintura de Karina Andrea Portilla Mendoza 
variedad, castellanizada como Borbón, se sembró abundantemente en Brasil y se conocería como "oro verde". La variedad Borbón se diferencia de la variedad Típica por ser más productiva, con un menor tamaño de los granos, pero con similar calidad potencial de la bebida. Estas variedades fundadoras se caracterizan por tener un porte alto: alcanzan alturas de tres metros al cumplir 24 meses de edad, cuando producen su primera cosecha significativa. Estas plantas pueden producir frutos por fecundación con su propio polen, una característica denominada autogamia, que resulta en cultivos muy homogéneos, ya que las plantas son muy parecidas entre sí.
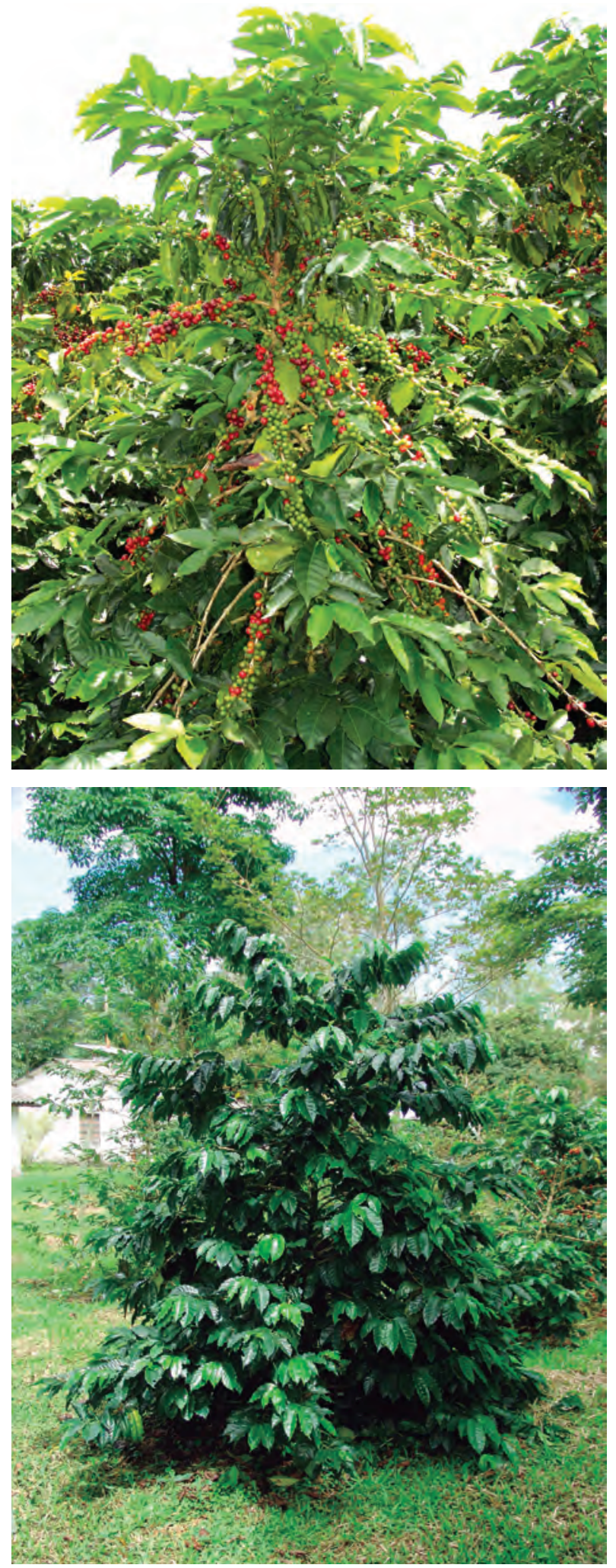

( Variedades de Coffea arabica de porte alto (típica, arriba) y de porte bajo (Colombia, abajo). Fotografías de Cenicafé 


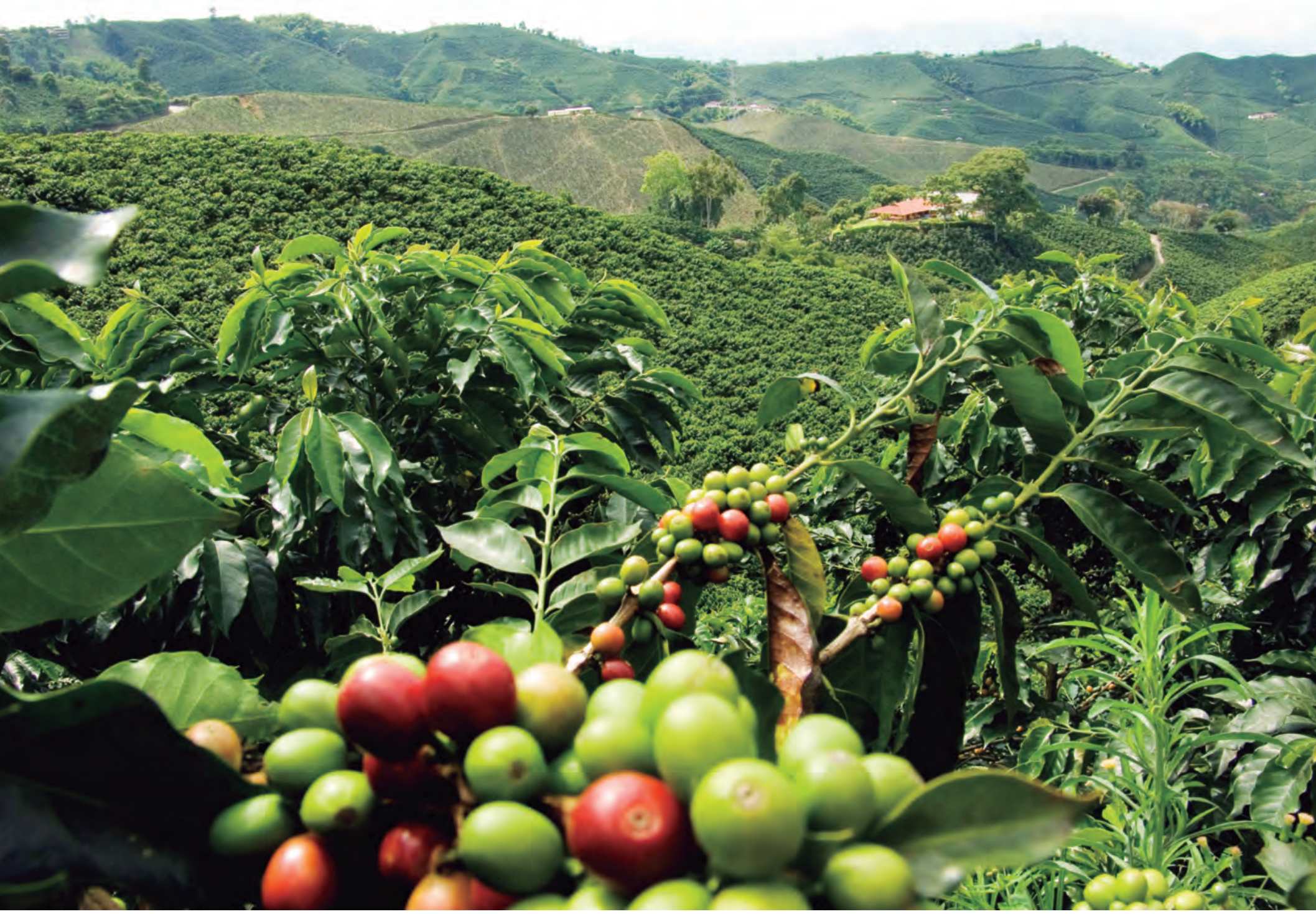

† Fructificación en la variedad Castillo. Departamento del Valle. Fotografía de Cenicafé

\section{O SOBRE LAS VARIEDADES Y LA CALIDAD}

Un cambio importante en la cultura del café se dio con la introducción de la variedad caturra, que resultó de una mutación natural de la variedad borbón, encontrada en plantaciones de Brasil. Esta variedad se caracteriza por presentar distancias más cortas entre las ramas y entre los nudos en las ramas, lo que produce plantas más compactas y de menor altura (1.5 metros) al culminar su desarrollo a los 24 meses de edad.

Estas condiciones permiten sembrarlas en mayor cantidad por hectárea y también facilitan la recolección de frutos a mano, lo que resulta en un aumento considerable de la productividad. La variedad caturra permitió la revolución verde de la caficultura colombiana, que consistió en una combinación de arbustos de porte bajo con mayores densidades de siembra (hasta 10000 plantas por hectárea), regulación de la luminosidad y aplicación de fertilizantes sintéticos al suelo.

El panorama de las plantaciones de café en Colombia cambiaría nuevamente con la llegada de la roya del cafeto, enfermedad causada por el hongo Hemileia vastatrix, que tiene un efecto devastador sobre las plantas, ya que les hace perder gran cantidad de hojas. La roya impide que los granos adquieran los nutrientes sintetizados en las hojas, necesarios para su desarrollo productivo y saludable.

Para la caficultura, la detección del primer lote de café afectado por la roya, en septiembre 
de 1983, significó el inicio de fumigaciones (aspersiones) de fungicidas basados en cobre para controlar el hongo. Pero fue principalmente la adopción de variedades resistentes a la enfermedad, como la variedad Colombia (1982), la variedad Castillo general, la Castillo regionales (2005) y, recientemente, la variedad Cenicafé 1 (2016), lo que marcó el uso de la biodiversidad como herramienta para obtener resistencia durable a la roya del cafeto. La mezcla de plantas genéticamente diversas ayuda a controlar y disminuir el ataque del hongo Hemileia vastatrix a los cafetales. Esta estrategia implica que morfológicamente las plantas puedan diferir en características como el color de los brotes de hojas, los ángulos de inserción de las ramas y la altura a los 24 meses de edad. Sin embargo, ha ayudado a disminuir substancialmente el uso de fungicidas en los cafetales en los últimos 35 años.

Para comienzos del 2018, el $50.5 \%$ de las 904000 hectáreas sembradas con café en el país correspondían a plantaciones de variedad Castillo general y sus regionales, el 26,5\% comprendía la variedad Colombia, y el 19\% restante estaba sembrado con variedad caturra, con muy pocas hectáreas cultivadas con las variedades de porte alto típica y borbón.

\section{O PRÁCTICAS CAFETERAS}

El segundo factor que influye en la calidad del café es el manejo agronómico, y en este aspecto Colombia ha tenido, durante toda su historia cafetera, lo que se ha denominado una "caficultura ambientalmente sostenible". Para comenzar, los cultivos son ubicados en lugares con rangos de temperaturas óptimos para los cafés arábigos (mínimo de 14 y máximo de $28^{\circ} \mathrm{C}$ ) a lo largo las laderas montañosas, cuya altura oscila entre los 1100 y los 2200 m, lo cual obliga a manejar de manera cuidadosa el suelo, por ser un recurso difícilmente renovable.

Los suelos de Colombia son muy ricos y diversos, pero también son muy sensibles a los efectos erosivos del agua y el viento, si no se manejan de manera adecuada, especialmente en la región andina. En la preservación de los suelos intervienen prácticas de cultivo como la siembra en curvas a nivel, la siembra en triángulo, el uso de árboles y otras barreras que evitan deslizamientos de masas rocosas, así como el manejo integrado de otras especies no arbóreas que comparten el nicho ecológico donde crece el café, y que genéricamente se conocen como arvenses (plantas

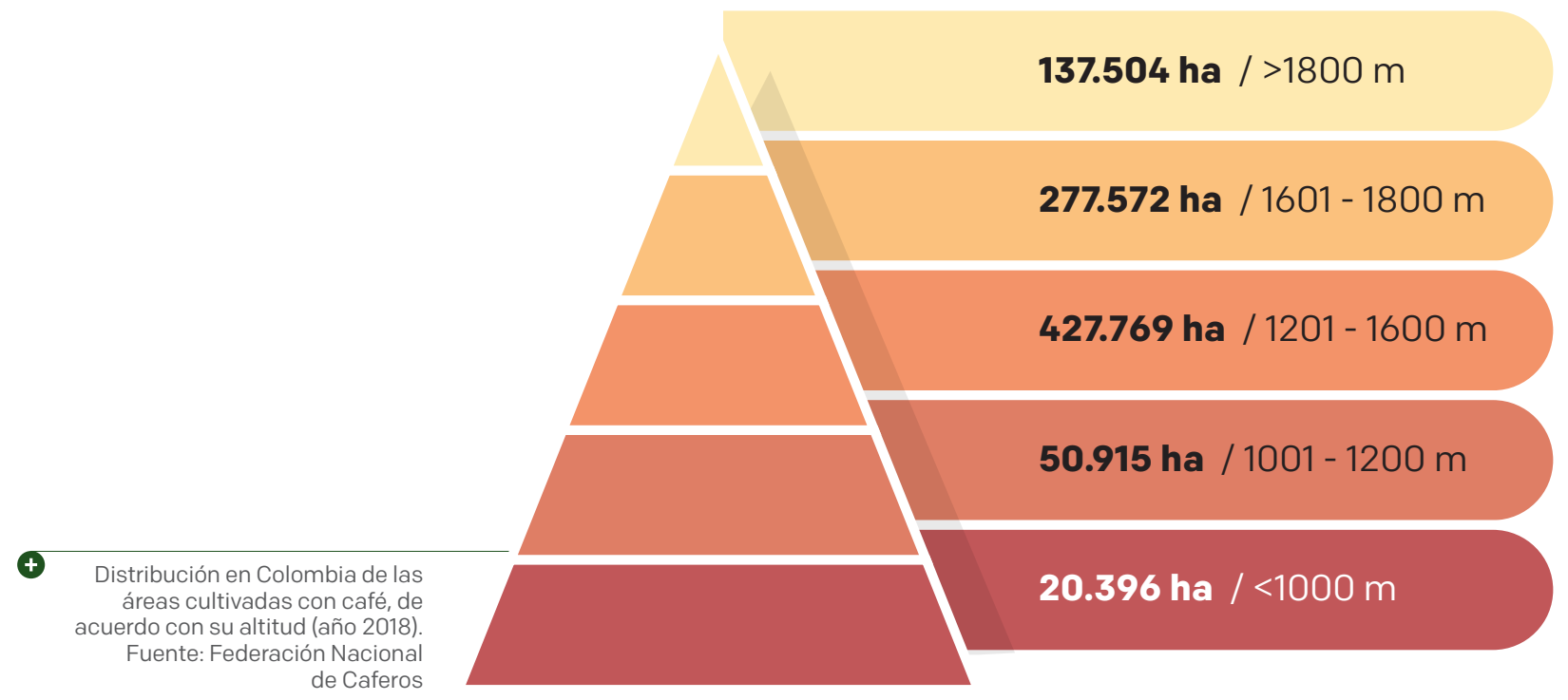


silvestres). La caracterización de arvenses de poca o ninguna competitividad con la planta de café permitió mantenerlas en el sistema de producción, ya que sus raíces ayudan a retener el suelo conteniéndolo como en una malla, y sus hojas y frutos sirven de albergue principal o alternativo a miles de especies de microorganismos e insectos. De esta forma, con una estrategia de manejo integrado de arvenses se logra pro- teger el suelo y se reduce el uso de herbicidas, lo cual se traduce en un beneficio económico y ecológico.

Con un enfoque muy similar, Colombia está utilizando el concepto de manejo integrado de plagas y enfermedades, donde se aplican de manera racional fungicidas y plaguicidas de síntesis química, y con apoyo en otras herramientas complementarias entre las que se encuentran:

\section{Control cultural}

A través del manejo de sombríos, del manejo integrado de arvenses o plantas silvestres, fertilizaciones adecuadas, repases en la cosecha (limpieza del cafetal)

\section{Control biológico}

Haciendo uso de enemigos naturales como insectos parasitoides, hongos entomopatógenos y micorrizas (término utilizado para la asociación que existe entre las hifas de los hongos y las raíces de las plantas)

\section{Control genético}

Que corresponde a variedades resistentes a enfermedades, en particular la roya del cafeto.

Este manejo integrado es muy importante en sistemas de producción en los que el caficultor vive con su familia en áreas inmediatamente aledañas a los cultivos de café, donde es común encontrar cultivos de seguridad alimentaria (plátano, maíz, fríjol, frutales), así como animales de cría, que se exponen directamente al contacto con los productos químicos aplicados. Por otra parte, la dependencia exclusiva de pesticidas para con- trolar las plagas y enfermedades (problemas fitosanitarios) trae asociados varios problemas, pues no solo aumenta los costos de producción, sino también el riesgo de que los organismos que se intenta controlar desarrollen resistencia, sin olvidar que también existe la posibilidad de que los granos de café queden impregnados con trazas de esas moléculas y se sobrepasen los niveles permitidos por los mercados internacionales. 


\section{○ PRIVILEGIOS TROPICALES}

El tercer factor que debe considerarse en la calidad de la bebida es el clima. A este respecto, Colombia se encuentra ubicada en el denominado cinturón del café, una zona que le da la vuelta al mundo y que se extiende $25^{\circ}$ al norte y $25^{\circ}$ al sur de la línea del ecuador, donde se encuentran todas las regiones productoras de café, incluyendo el sur de China (Yunán) y el norte de Australia (Queensland).

Por su ubicación ligeramente al norte de la línea del ecuador y la presencia de las regiones montañosas que dan como resultado los más bellos y extremos paisajes, Colombia es el país con mayor similitud geográfica a Etiopía, sitio de ori- gen del café. Ante la ausencia de estaciones en las zonas tropicales, las montañas y la distribución de las lluvias son la fuente de la diversidad en la oferta ambiental, lo cual genera no solamente rangos amplios de temperatura, de acuerdo con la altitud, sino también condiciones que determinan patrones locales de iluminación, humedad y lluvias, así como una composición y estructura de los suelos que varía en distancias relativamente cortas. En este último aspecto, Colombia cuenta con un factor adicional, pues en las entrañas de las imponentes montañas andinas se gestan los más exuberantes volcanes, cuyas cenizas cubren extensas regiones, sumando variabilidad a las características de los suelos usados para producir café.

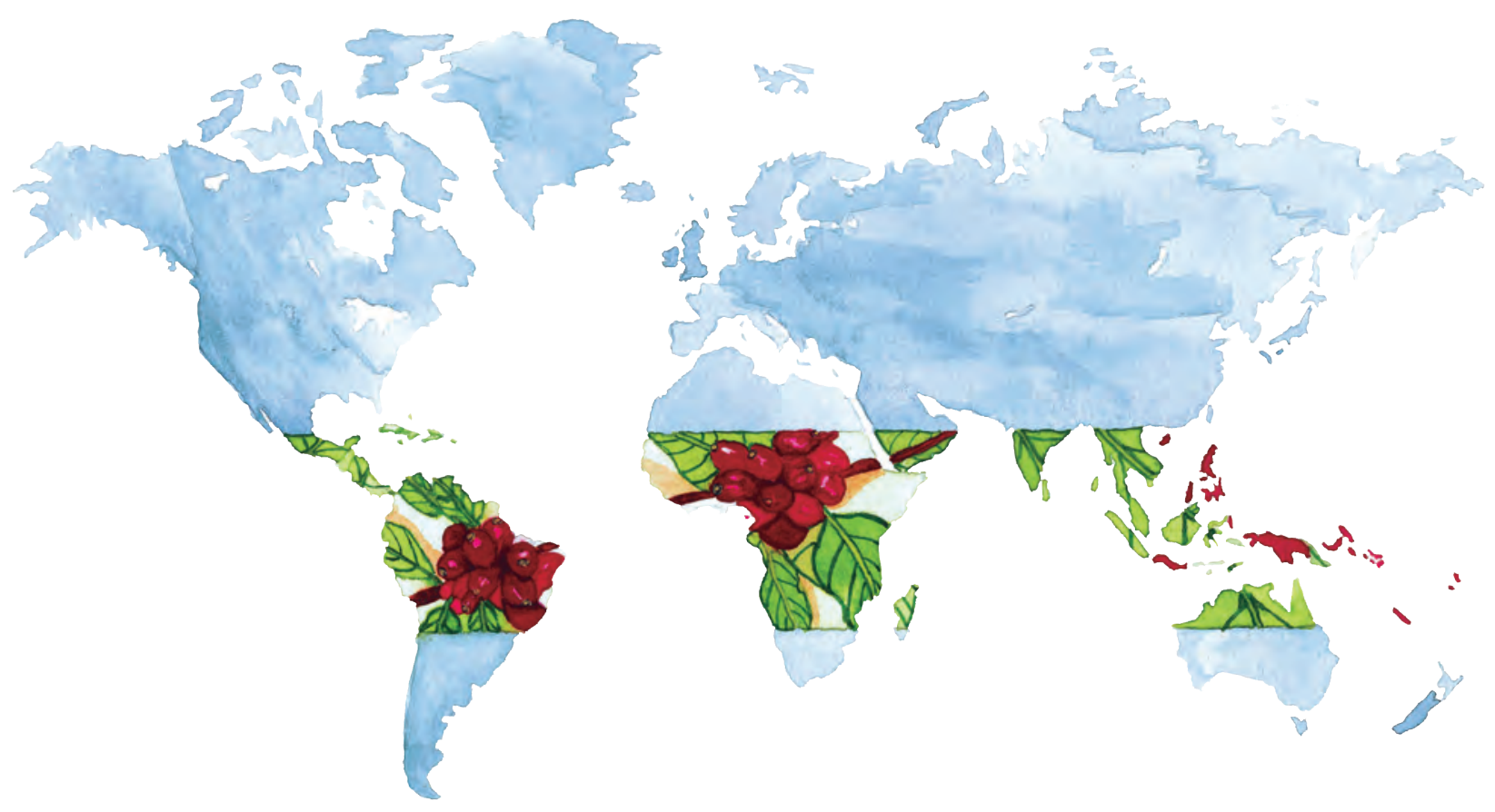

Cinturón del Café donde se observa la distribución de las zonas cafeteras en el mundo.

Pintura de Karina Andrea Portilla Mendoza 
La distribución de las lluvias en Colombia está gobernada por el recorrido anual de la zona de confluencia intertropical (ZCIT), un frente originado por el encuentro de la atmósfera del hemisferio norte y la del hemisferio sur en la región ecuatorial, que arrastran masas de humedad que finalmente se precipitan como lluvia. La ZCIT se ubica en el sur del país al iniciar el año y se desplaza hacia el norte, hasta llegar a la costa caribe, hacia mitad de año, para comenzar su retorno al sur. Este desplazamiento tiene dos consecuencias en cuanto a los períodos de lluvias y de sequías:

1. Divide al país en tres zonas, según su distribución de precipitación: una monomodal en el sur, donde las lluvias principales ocurren en el primer semestre del año; una bimodal, hacia el centro del país, con dos periodos de Iluvia importantes en abril-mayo y en noviembre-diciembre, y una zona norte monomodal, con altas precipitaciones en el segundo semestre del año. El comportamiento de la zona norte se extiende también a la vertiente oriental de la cordillera Oriental, influida por la Orinoquia y la Amazonia.

2. El movimiento latitudinal de la ZCIT sobre Colombia es uno de los más estrechos en el mundo, por lo que el país no experimenta periodos secos muy marcados, como los que ocurren en Brasil o Centroamérica. Este hecho incide en la floración de las plantas de café que, ante la presencia continua de lluvias, se dispersa en varios eventos a lo largo del año, reduciendo la ocurrencia de cosechas, concentradas

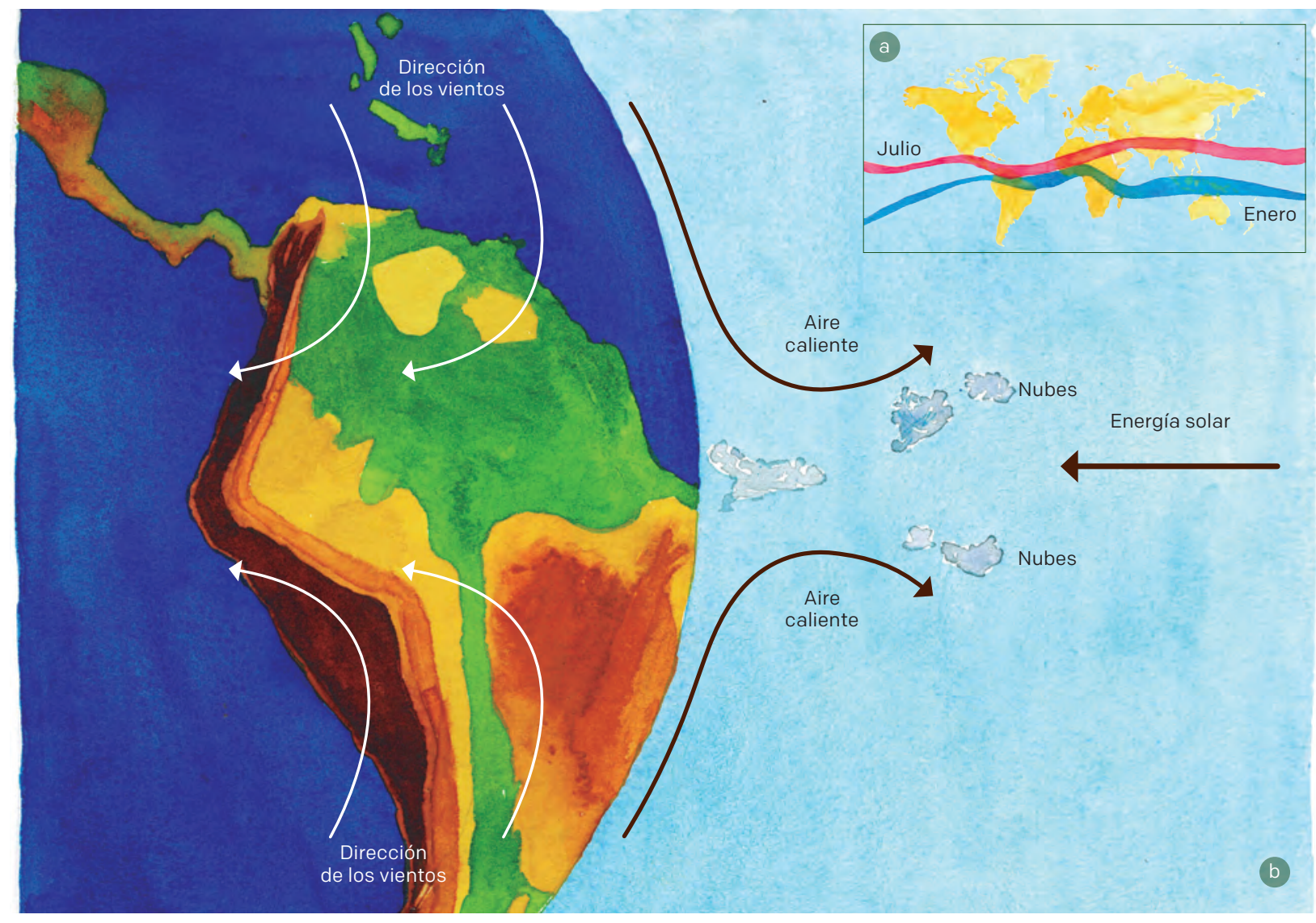

+ a. Localización de los vientos intertropicales a lo largo de la ZCIT y su trayectoria por nuestro país durante los meses de julio y enero. Nótese cómo su posición cambia a lo largo del año. b. Dinámica de los vientos, formación de nubes y ocurrencias de lluvias en la ZCIT

a. Tomado y modificado Wikipedia: https://en.wikipedia.org/wiki/File:ITCZ_january-july.png Pintura de Karina Andrea Portilla Mendoza 
nueve meses después, y obliga a realizar una recolección selectiva de cerezas maduras de café, pues se pueden encontrar frutos en diferentes estados de desarrollo en una misma rama que ha tenido numerosos eventos de floración.

La ausencia de extensos periodos secos favorece la dispersión y también vuelve al cafeto vulnerable a la roya, lo que hace de Colombia una región muy susceptible al ataque de esta enfermedad.

Sin embargo, de esta situación se deriva un beneficio para los amantes de una buena taza de café: justamente esta distribución de lluvias a lo largo del país permite producir café fresco para el mundo durante todo el año, lo que hace muy apreciado al grano colombiano.

La ZCIT no es el único factor que determina las condiciones climáticas de la zona cafetera colombiana. Por su ubicación geográfica en la esquina nororiental suramericana, Colombia está influida por el mar Caribe, por las llanuras de la Orinoquia, por la humedad de la Amazonia, y especialmente por los fenómenos que se generan en el océano Pacífico, en particular, las oscilaciones de El Niño y Decadal del Pacífico.

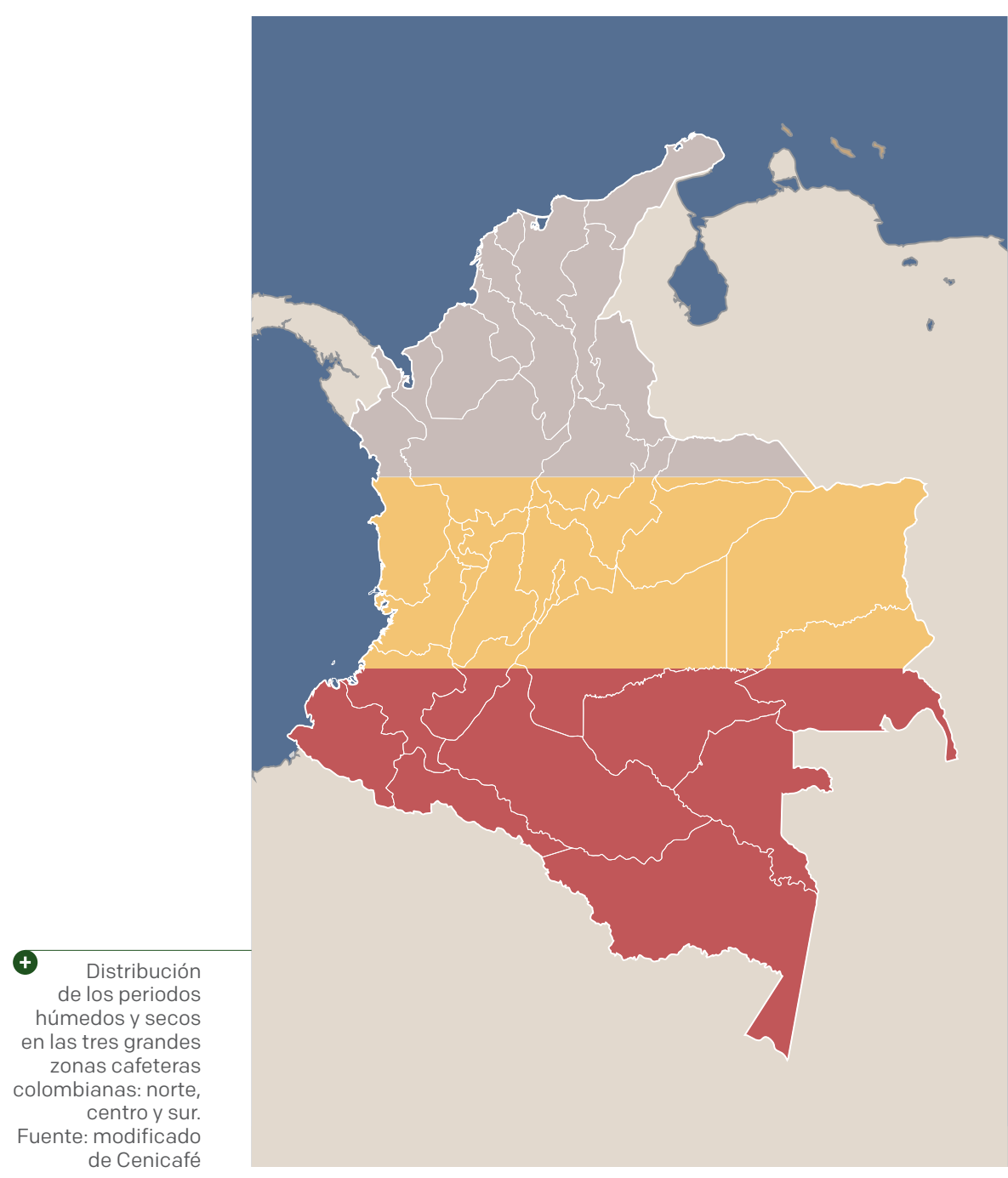

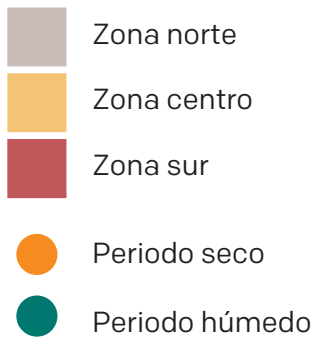

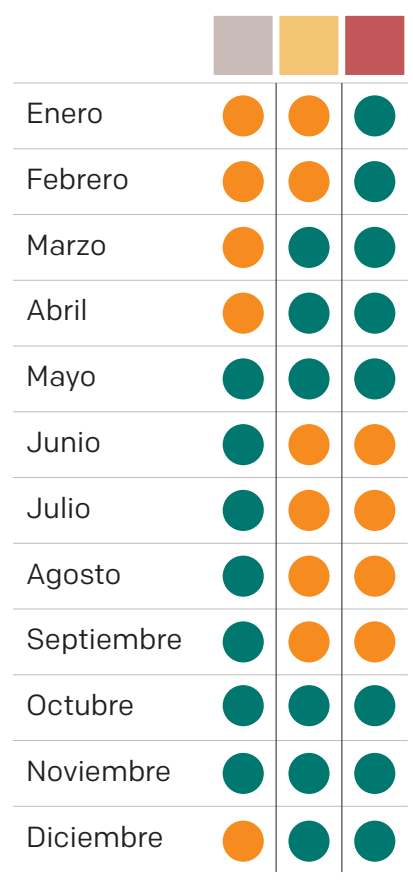




\section{- COSECHANDO CAFÉ}

El siguiente factor que influye en la calidad de la bebida es la calidad de la cosecha, que en Colombia se relaciona directamente con la selección de frutos maduros y sobremaduros en el momento de retirarlos de las ramas.

Este factor está determinado por la continua ocurrencia de lluvias en las zonas cafeteras, especialmente en la región central, que estimula al mismo tiempo el crecimiento vegetativo (nuevos nudos y nuevas hojas) y el crecimiento reproductivo (nuevos botones florales y frutos en diferentes estados de desarrollo).

La ausencia de floraciones y maduraciones sincronizadas en los árboles obliga a pasar varias veces por el mismo lote realizando una cosecha manual, durante la cual los recolectores identifi- can visualmente las cerezas en estados adecuados de maduración, en una labor que demanda mucha mano de obra y que constituye entre un 40 y un $50 \%$ de los costos de producción de café. Pases de cosecha en los que se presente un porcentaje de frutos verdes mayor que el $2.5 \%$ van a tener un potencial de bebida de calidad inferior, con defectos como suciedad, fermento, mal olor, tierra y otros.

Esta necesidad de realizar una cosecha selectiva, sumada a la ubicación de los cafetales en laderas con pendientes mayores al 30\% y a la ocurrencia de lluvia durante los meses de maduración del grano, complica el movimiento de maquinaria en terrenos muy húmedos. Esto hace muy difícil la implementación de métodos de cosecha mecanizada o semimecanizada que reduzcan la necesidad de mano de obra y, por ende, los costos.

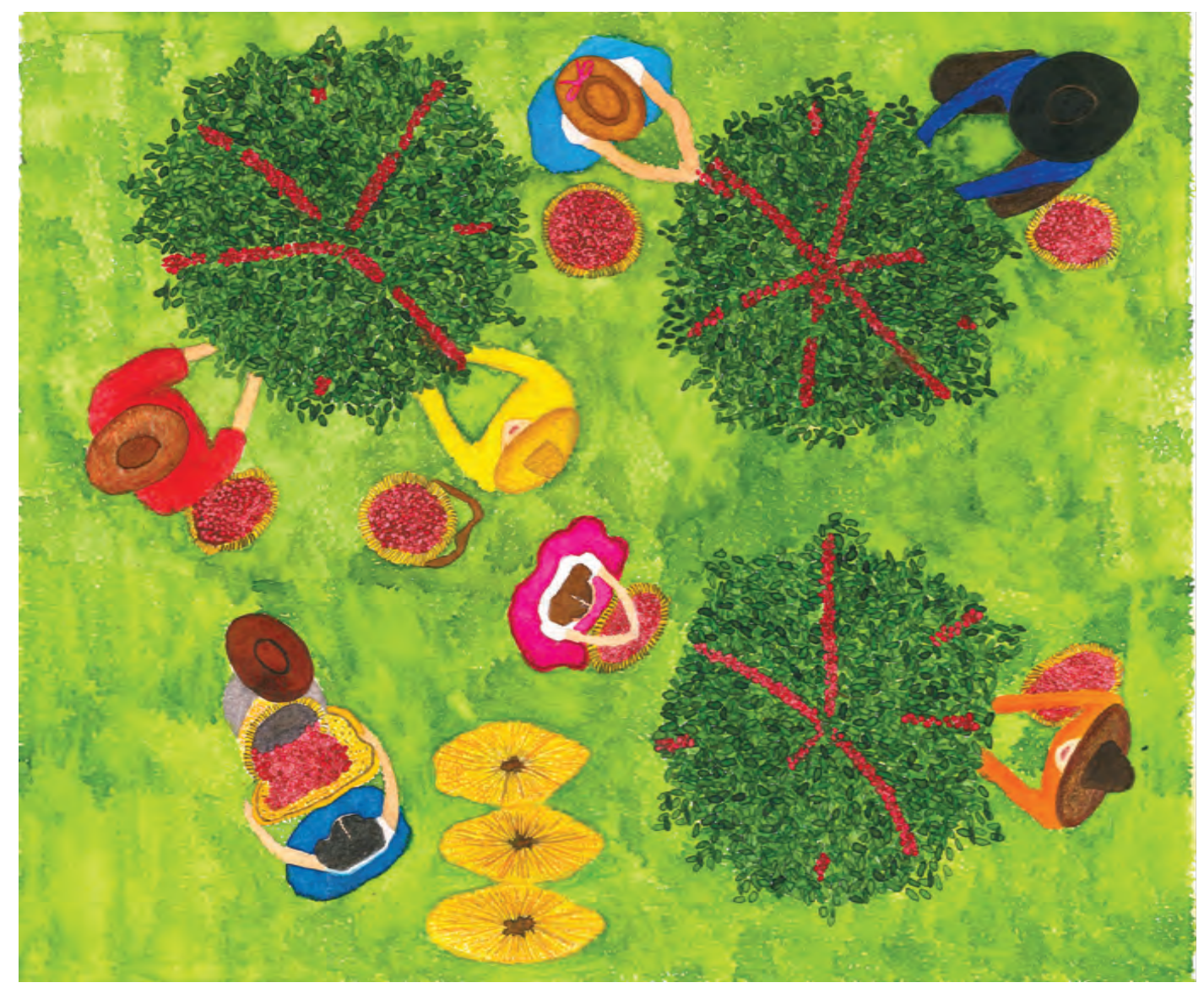

- Grupo de recolectores en una cosecha de frutos maduros y sobremaduros de café 


\section{- DE CEREZA A PERGAMINO}

Finalmente, entre los factores que influyen en la calidad de la bebida, partiendo de su lugar de origen en las fincas productoras de café, se encuentra el proceso de beneficio, que consiste en transformar la cereza en dos granos de café pergamino seco.

En el mundo hay dos procesos básicos de beneficio de café: uno es el beneficio seco, muy común en sitios donde coincide la cosecha con periodos de humedad relativa baja y sin precipitaciones por espacio de varios días. En este caso,

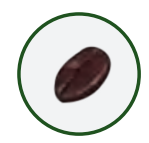

Café tostado: granos de café después de la aplicación de calor, lo que potencializa el aroma y sabor.

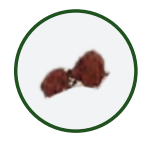

Café molido: café resultante de la molienda antes de la preparación de la bebida, que puede ser de tipo grueso, fino y medio.

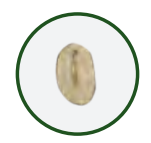

Café verde: también llamado "café oro" "semilla" o "almendra" y se obtiene después de la remoción del pergamino durante la trilla. Con este se elabora el café tostado, el soluble y los extractos. Forma común en la que se exporta la mezcla de frutos maduros, sobremaduros y secos (incluido un porcentaje de frutos verdes) se cosecha y se deja secar al sol hasta que la cáscara o pulpa deshidratada queda adherida a los granos de café. Este proceso es muy usado en Brasil, y su resultado son los llamados "cafés naturales".

Por otro lado, el beneficio húmedo, característico del café lavado colombiano, se inicia con la remoción mecánica de la cáscara en una despulpadora, que deja el grano de café desnudo, pero cubierto de una capa gelatinosa llamada mucílago. Tradicionalmente, este mucílago se remueve mediante una fermentación aeróbica realizada

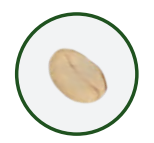

Café pergamino seco: semilla del café protegida por el pergamino, que resulta después del beneficio y es el estado del grano en el cual lo cafeteros venden su cafe

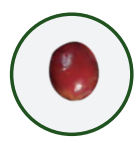

Café y cereza: fruto maduro y es el estado óptimo en que debe ser recolectado para aprovechar su calidad. 
en horas de la noche por poblaciones de bacterias y levaduras, para lo cual los granos de café se sumergen en un tanque de agua. Hasta la década de los noventa, la fermentación y el lavado posterior en canales de correteo elevaban el consumo total de agua a 40 litros o más por cada kilogramo de café procesado. Sin embargo, a medida que las regulaciones ambientales se han vuelto más estrictas con el uso del agua, y los consumidores exigen menor afectación ambiental, se han desarrollado tecnologías como el tanque tina, el desmucilaginador mecánico (Becolsub), que no requiere de fermentación, y la fermentación sin agua añadida (Ecomill $\left.{ }^{\circledR}\right)$, que soportan el concepto del beneficio ecológico mediante la combinación de estrategias para consumir menos de 10 litros por kilogramo de café cereza.

Una vez lavado, el café contiene un 53\% de agua, que lo hace un sustrato adecuado para la proliferación de microorganismos, en particular, hongos, que pueden afectar su calidad y su inocuidad cuando producen sustancias como las ocratoxinas. Por esta razón es necesario proceder de manera inmediata a reducir el porcentaje de humedad del grano, hasta llegar a un rango entre el 10 y el $12 \%$. La forma más sencilla de secar el grano es usando la radiación solar y la energía natural del aire ambiente, lo que puede demandar entre quince y veinte días, dependiendo de las condiciones climáticas. Estas fuentes de calor se pueden aprovechar de manera más eficiente usando secadores parabólicos y tipo túnel, que reducen el tiempo en una tercera parte. Cuando los volúmenes o las condiciones climáticas hacen difícil el secado solar, se acude al secado mecánico, con tambo- res (guardiolas) o silos secadores que funcionan con combustión de madera, cisco o gas, o, eventualmente, a métodos de secado que combinan la energía solar y procedimientos mecánicos para reducir, aún más, tiempos y costos.

Por su parte, la aplicación de buenas prácticas de beneficio, que contemplan el uso de instalaciones y equipos en adecuado estado de limpieza, además de fermentaciones y lavados en aguas que cumplan con las condiciones químicas y microbiológicas requeridas para el procesamiento de un producto destinado a consumo humano, contempla el retorno del agua utilizada al medio ambiente para permitir su reutilización. Con este fin, la caficultura de Colombia, además de reducir el volumen de agua requerido para el transporte de la pulpa, para el mismo despulpado y para el proceso de fermentación, ha utilizado procesos de descontaminación como el sistema de tratamiento modular anaerobio (STMA). Este sistema reduce el rango de contaminación de 115 gramo por kilogramo de frutos de demanda química de oxígeno, a un rango entre los 10 y 30 gramo por kilogramo de frutos, mediante la fermentación de las aguas de lavado, o "aguas mieles", en tanques y un tratamiento posterior en un lecho húmedo con plantas acuáticas.

En Colombia, luego de realizar el beneficio del café, el productor tradicionalmente vende el "café pergamino seco" a las cooperativas o a compradores privados, y estos proceden a remover tanto el pergamino, que corresponde al cisco o cascarilla, como la película plateada (en total, un $20 \%$ del peso seco) mediante la trilla, para dejar el grano de "café verde" de exportación. 


\section{- LA FAMILIA CAFETERA COLOMBIANA}

Además de su calidad, el café de Colombia tiene otra gran particularidad: sus productores. Para 2018 se encontraban registradas 541000 familias productoras en el Sistema de Información Cafetera (SICA), quienes manejaban casi dos millones de lotes de café, que sumaban 904000 hectáreas, donde, entre 2015 y 2018 , se han producido anualmente 14 millones de sacos de café verde de 60 kilos para el consumo local y mundial.

El 96\% de los cafeteros colombianos produce en áreas menores de cinco hectáreas, y ocupan con café un $74 \%$ del área sembrada. Esto corresponde a una economía familiar en la que el productor aporta una gran parte de la mano de obra requerida para el cultivo, la cosecha y el beneficio del grano.

Por esto, en Colombia el panorama de las zonas productoras de café se compone de pequeños lotes de diferentes edades y densidades de siembra, acompañados de bosques y de guaduales que protegen las fuentes de agua y que le dan al paisaje una apariencia de colcha de retazos.

Colombia es un ejemplo para el mundo agrícola por la organización de su sector cafetero desde 1927, cuando se fundó la Federación Nacional de Cafeteros, una entidad sin ánimo de lucro que trabaja por el bienestar de los caficultores y sus familias, y que administra el Fondo Nacional del Café, un recurso público construido con la contribución de seis centavos de dólar estadounidense por cada libra de café verde exportada. Con estos recursos se ejerce la garantía de compra, un mecanismo ideado para brindar un precio justo y un pago inmediato en efectivo al productor. Este mecanismo asegura al caficultor la comercialización

\section{$+$}

Panorama típico de la caficultura de Colombia, con lotes de café menores de una hectárea, en diversos estados de renovación y entremezclados con fragmentos de bosque y zonas de protección de fuentes de agua. Buena Vista, Quindío.

Fotografía de la Federación Nacional de Cafeteros

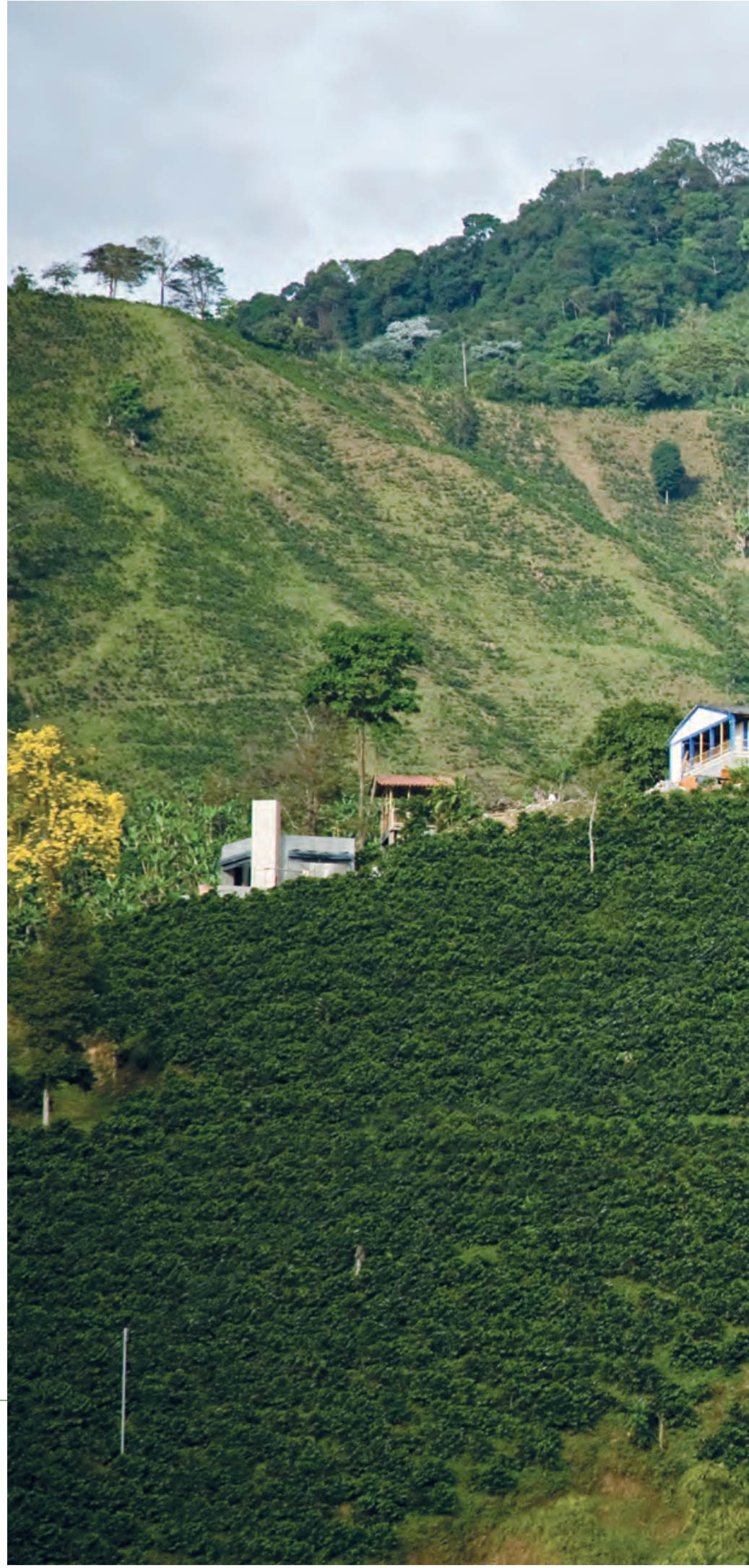




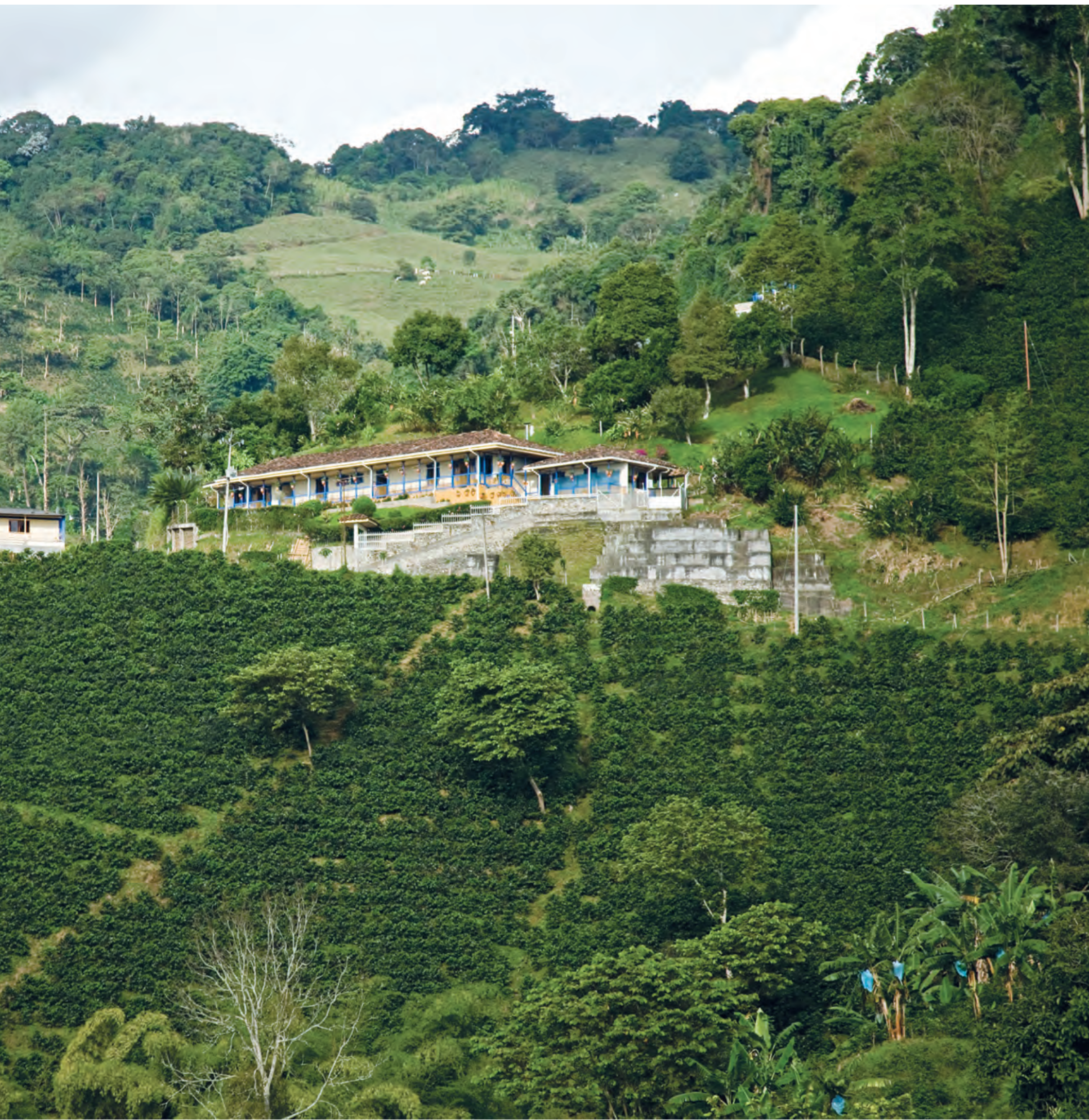


de su café en más de quinientos puntos de compra en todo el país, y con dos actualizaciones de precio diarias con base en la cotización del producto en la Bolsa de Nueva York. Igualmente, con los recursos del Fondo se financia la investigación científica, ajustada a las condiciones de Colombia, realizada por el Centro Nacional de Investigaciones de Café (Cenicafé), que nutre de información el Servicio de Extensión Rural, un equipo especializado para motivar, instruir y apoyar al caficultor en la toma de decisiones respecto a sus sistemas productivos. Finalmente, el Fondo financia también la promoción del café de Colombia en el exterior, actividad encabezada por un personaje icónico de la caficultura: Juan Valdez.

En su conjunto, la actividad económica generada por la caficultura es un factor de bienestar social en los 509 municipios donde se produce café en Colombia. Los más de 2000 millones de dólares que cuesta la producción anual de café se distribuyen en las zonas rurales, donde se cuidan para el futuro los recursos naturales que les permitirán, a la tierra colombiana y a sus caficultores, seguir produciendo un café de alta calidad para degustar en todo el mundo.

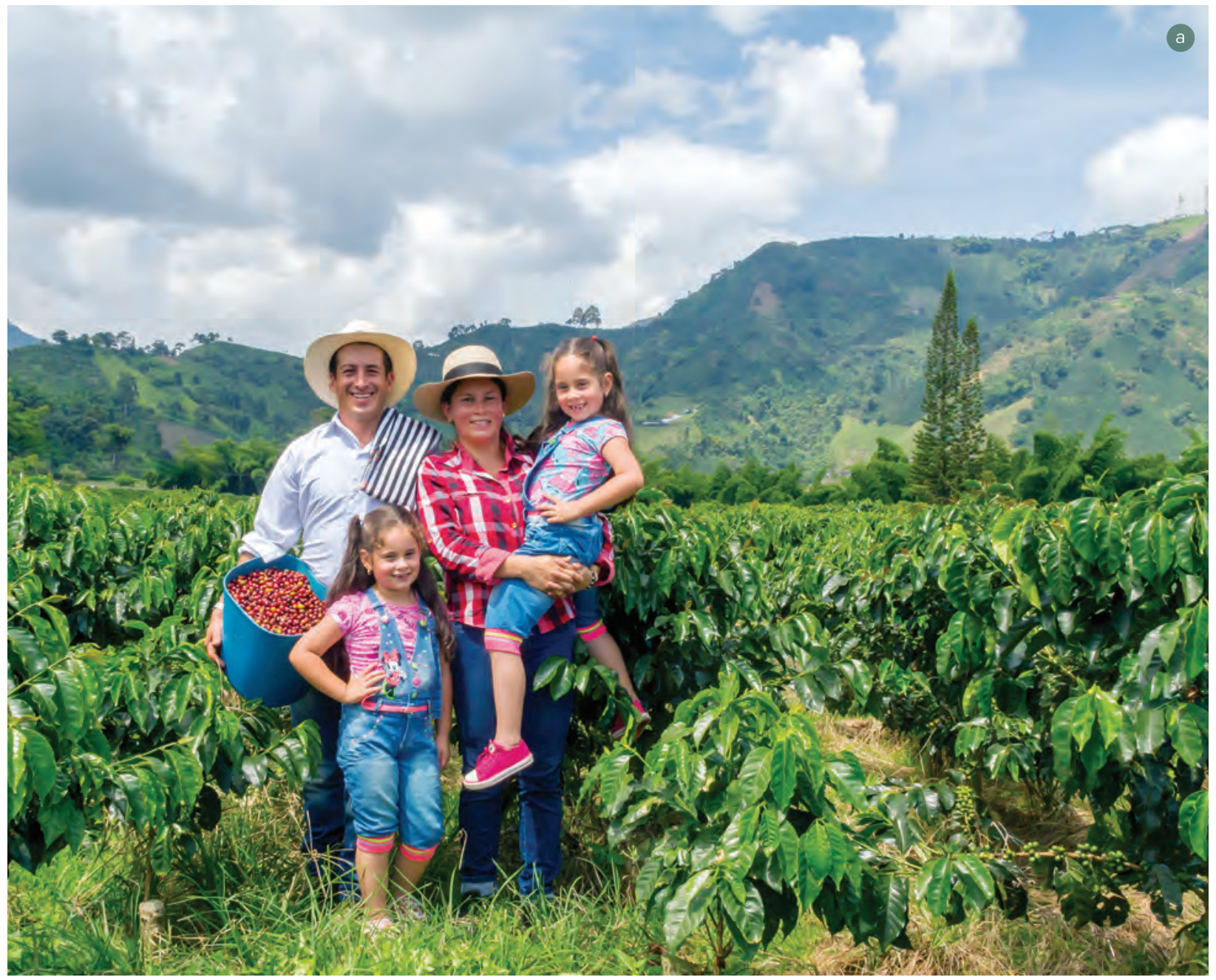

† Familias cafeteras colombianas. (a) Familia en Antioquia, (b) Familia en norte de Santander y (c) Familia González Castaño. Fotografías de la Federación Nacional de Cafeteros 


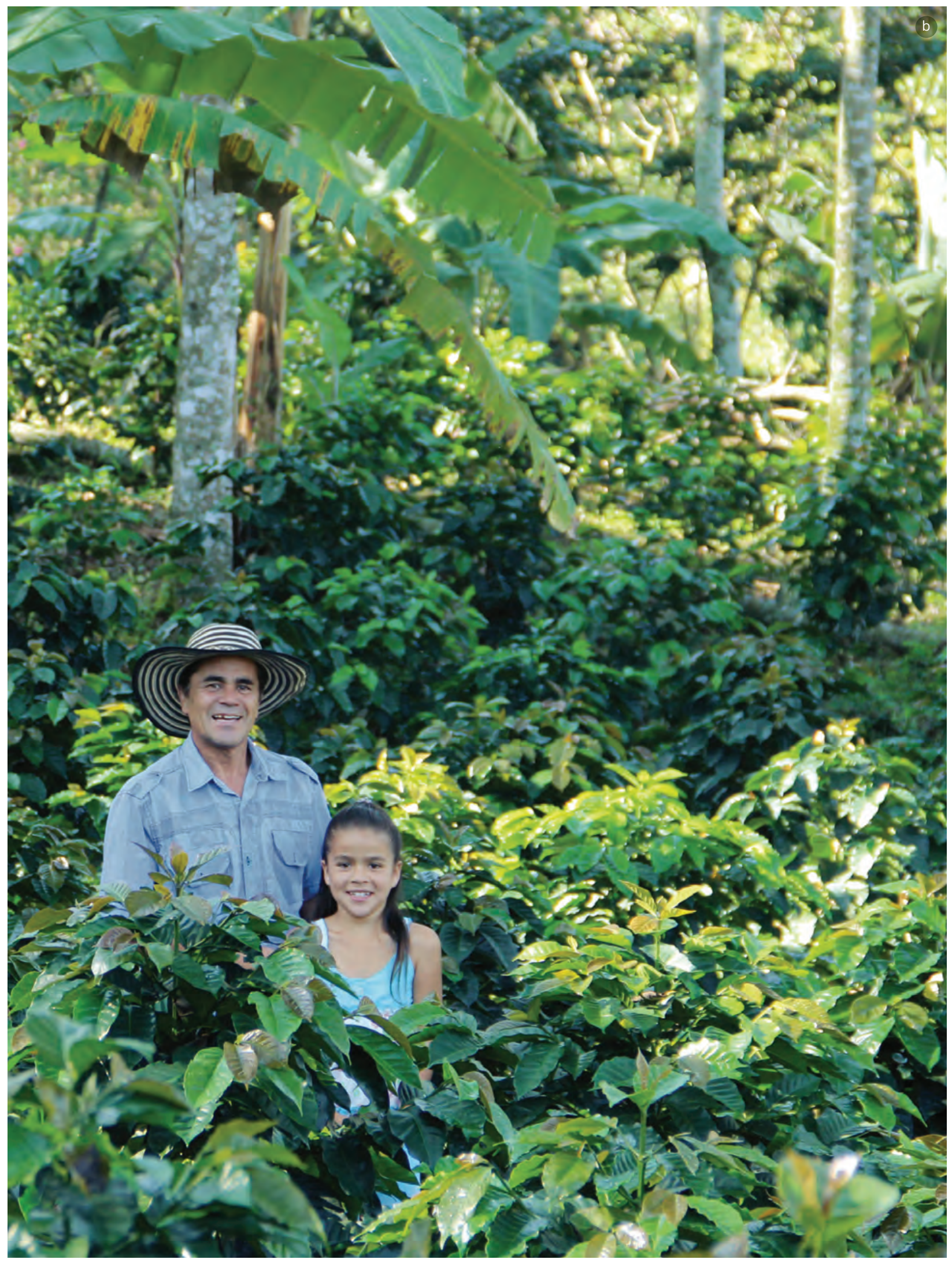




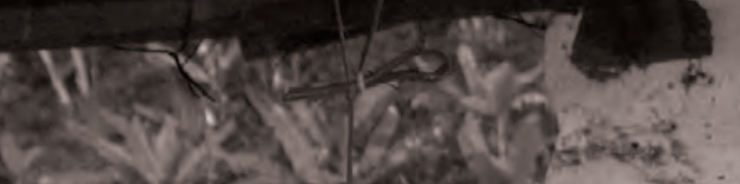

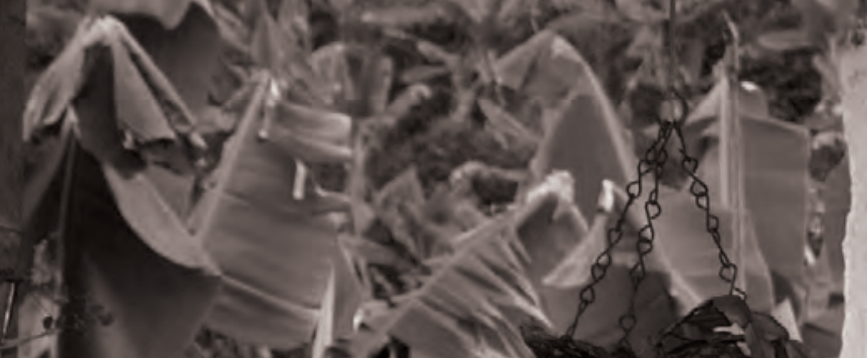
and

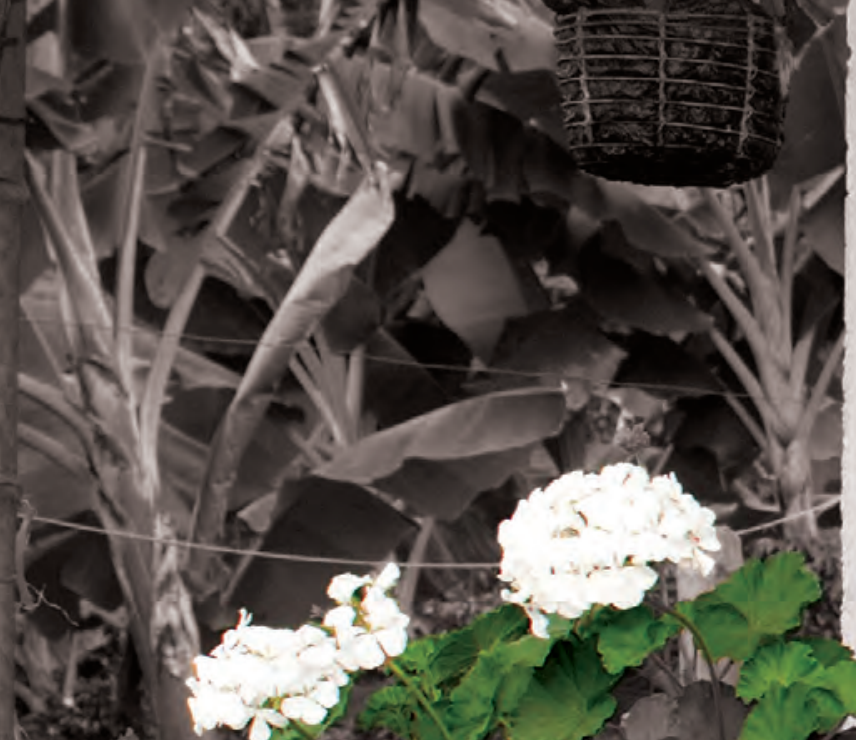

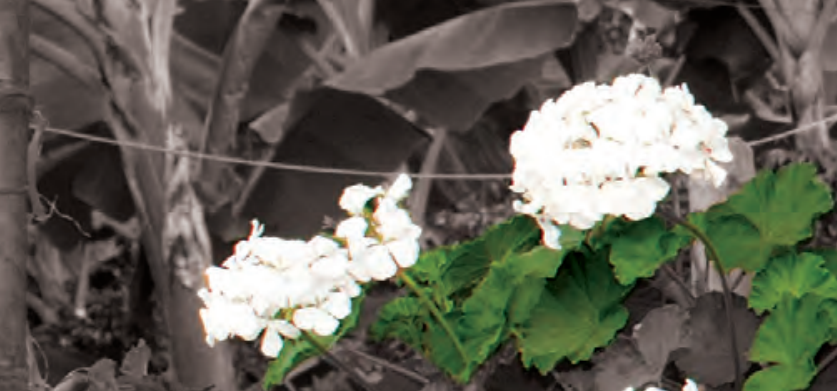
- $82 x-20$

An of 5 की 3. 


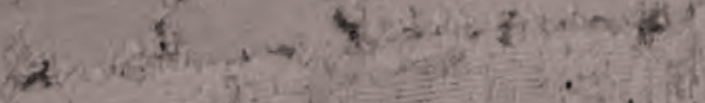

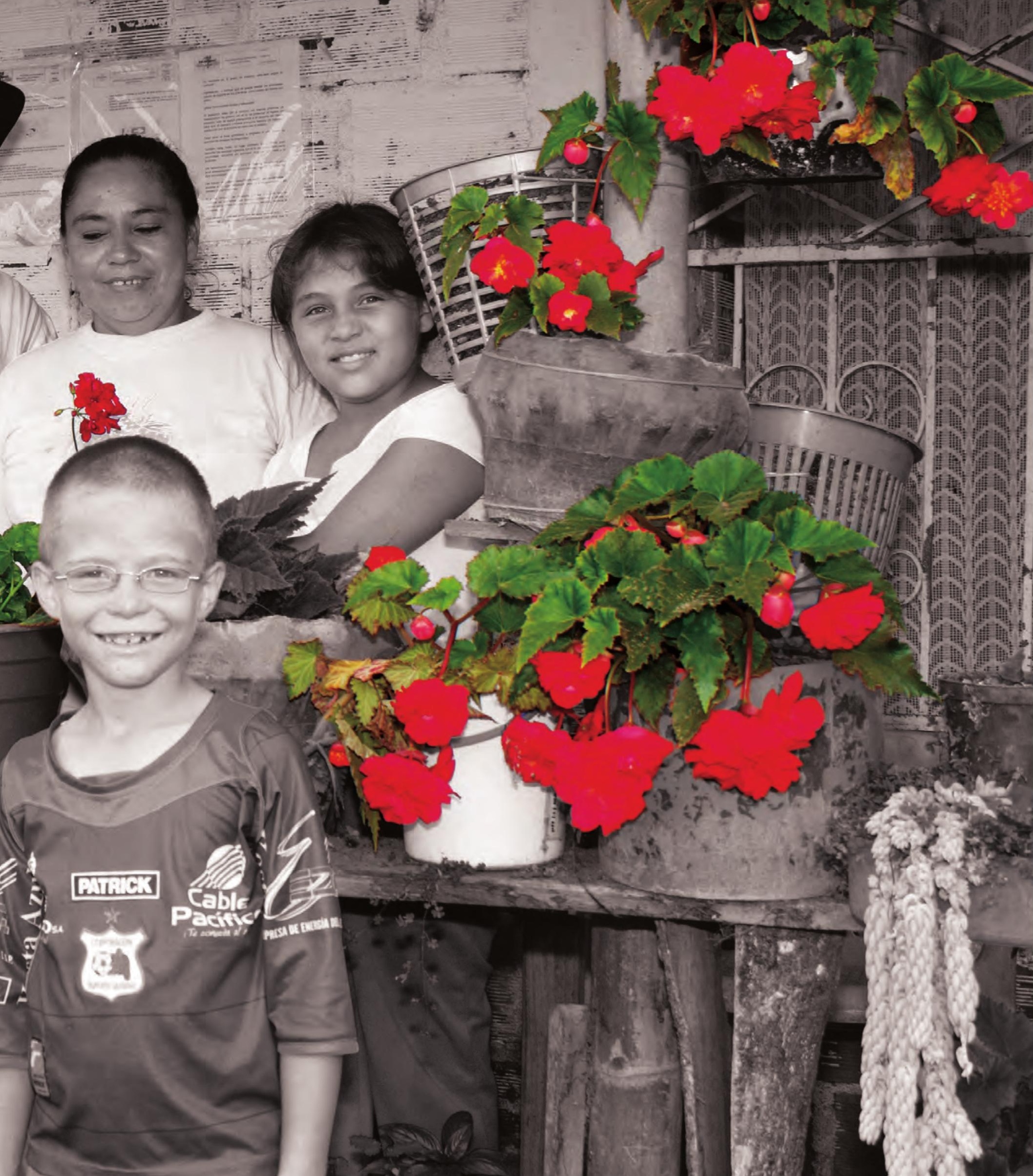


